Supporting Information

Aptamer-Based Sensing of Small Organic Molecules by Measuring Levitation

Coordinate of Single Microsphere in Combined Acoustic-Gravitational Field

Akihisa Miyagawa, Yusuke Okada, and Tetsuo Okada*

Department of Chemistry, Tokyo Institute of Technology, Meguro-ku, Tokyo 152-8551,

Japan.

Figure S1 Relationship between the number of AuNPs bound on a PMMA ( $\left.n_{\text {AuNP/PMMA }}\right)$ and $\Delta z$

Determination of the limit of detection.

Figure S2 Relationships between $\Delta z^{\prime}$ and the logarithmic concentrations of ATP, DA, and AMP in the low concentration ranges.

Figure S3 Relationship between $\log K_{1}$ and the number of AuNPs bound on a PMMA at

$$
r_{\mathrm{AuNP} / \mathrm{PMMA}}=10000 \text {. }
$$

Figure S4 Relationships between the $\log c$ for ATP and the reaction ratio. The curve represents the result of calculation assuming 1:2 aptamer-ATP complexation.

Figure S5 Experimental setup. 


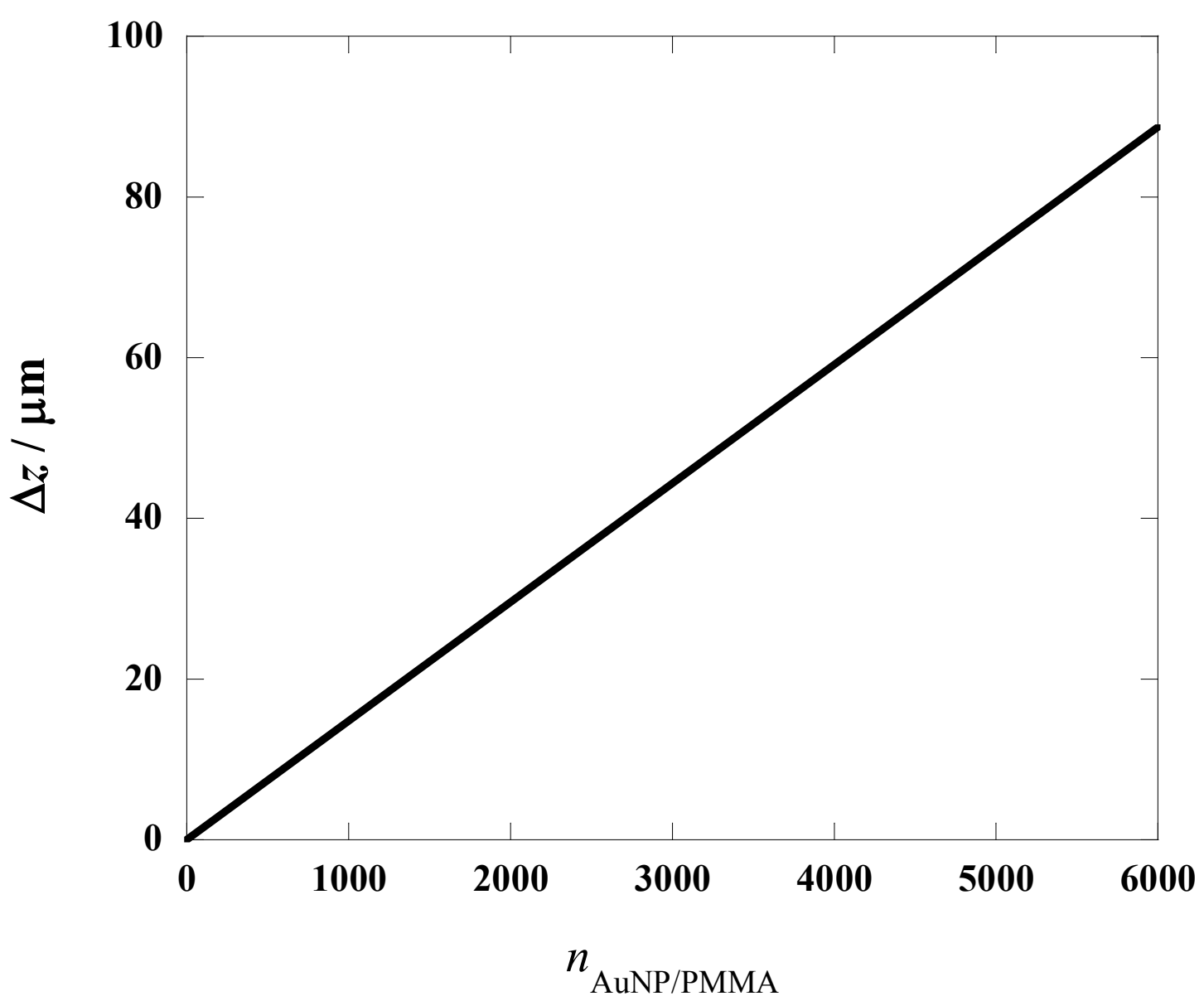

Figure S1 Relationship between the number of AuNPs bound on a PMMA ( $\left.n_{\text {AuNP/PMMA }}\right)$ and $\Delta z$

This relation was calculated using Equations (1) and (2) with parameters; $a=0.040, E_{\mathrm{ac}}$ $=22.5 \mathrm{~J} \mathrm{~m}^{-3}, \rho^{\prime}(\mathrm{PMMA})=1.188 \mathrm{~g} \mathrm{~cm}^{-3}, \rho^{\prime}(\mathrm{Au})=19.32 \mathrm{~g} \mathrm{~cm}^{-3}$, and $\gamma($ PAMMA $)=$ $1.54 \times 10^{-10} \mathrm{~Pa}^{-1}$. 


\section{Determination of LOD}

$\Delta z$ was converted to $\Delta z$ ' by the following equation.

$$
\Delta z^{\prime}=-\left(\Delta z-\Delta z_{0}\right)
$$

where $\Delta z_{0}$ is $\Delta z$ determined for AuNP-bound PMMA in the absence of the target

molecule. Figure S3 shows linear relationships between $\Delta z^{\prime}$ and the logarithmic

concentrations of the targets as represented by the following equations:

$$
\begin{aligned}
& \Delta z^{\prime}=-8.08+17.6 \log \left(c_{\mathrm{ATP}} / \mathrm{nM}\right), \text { for } c_{\mathrm{ATP}}=1 \mathrm{nM}-1000 \mathrm{nM} \\
& \Delta z^{\prime}=-23.1+26.4 \log \left(c_{\mathrm{DA}} / \mathrm{nM}\right), \text { for } c_{\mathrm{DA}}=1 \mathrm{nM}-500 \mathrm{nM} \\
& \Delta z^{\prime}=34.6+31.9 \log \left(c_{\mathrm{AMP}} / \mathrm{nM}\right), \text { for } c_{\mathrm{AMP}}=0.1 \mathrm{nM}-10 \mathrm{nM}
\end{aligned}
$$

LOD values were determined by these equations and $3 \sigma(\sigma=3.12 \mu \mathrm{m})$ at $\Delta z^{\prime}=0$.

Thus, the LODs for ATP, DA, and AMP were determined to be $9.8 \mathrm{nM}, 17 \mathrm{nM}$, and 160 $\mathrm{pM}$, respectively. 

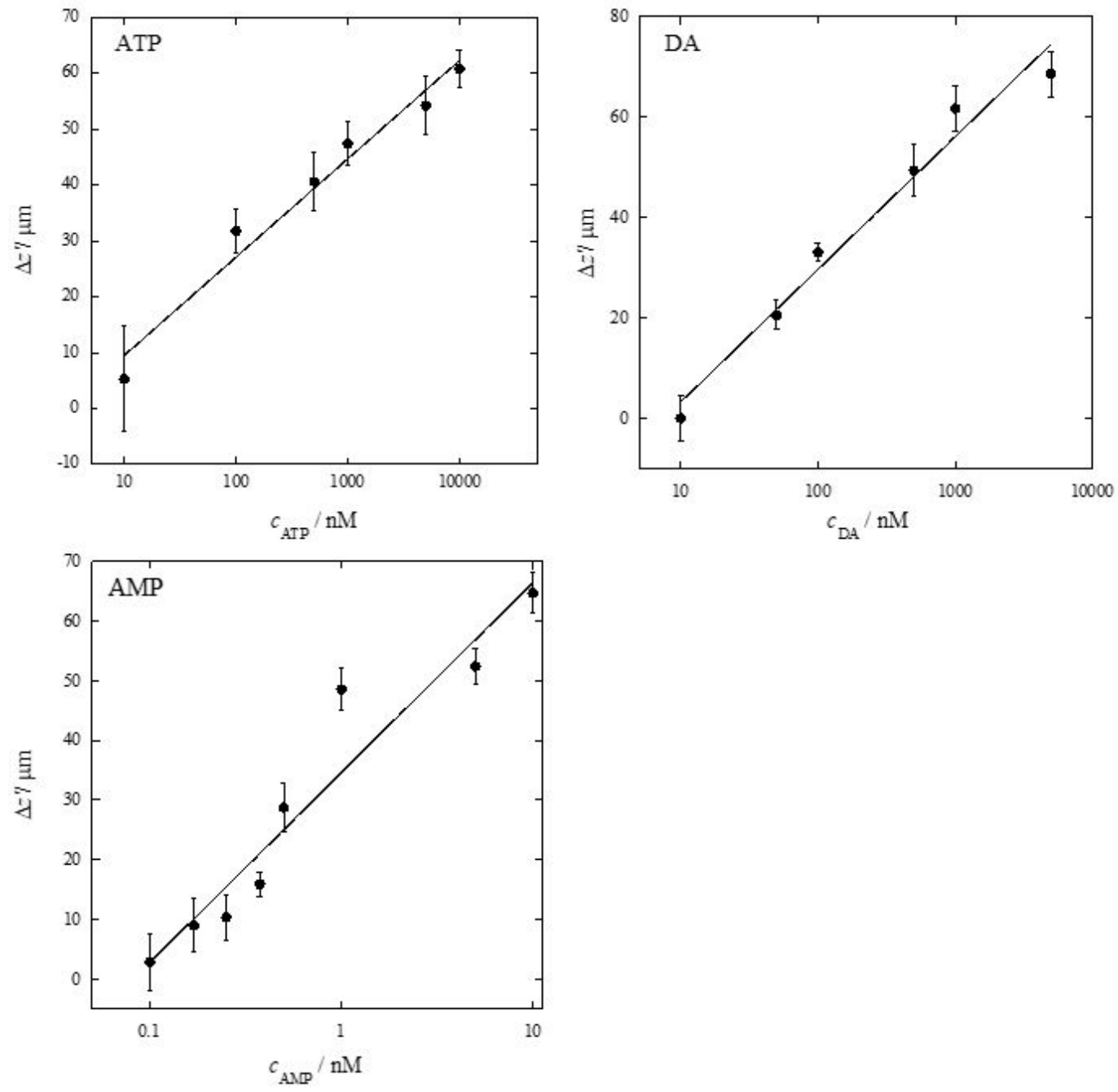

Figure S2 Relationships between $\Delta z^{\prime}$ and the logarithmic concentrations of ATP, DA, and AMP in the low concentration ranges. 


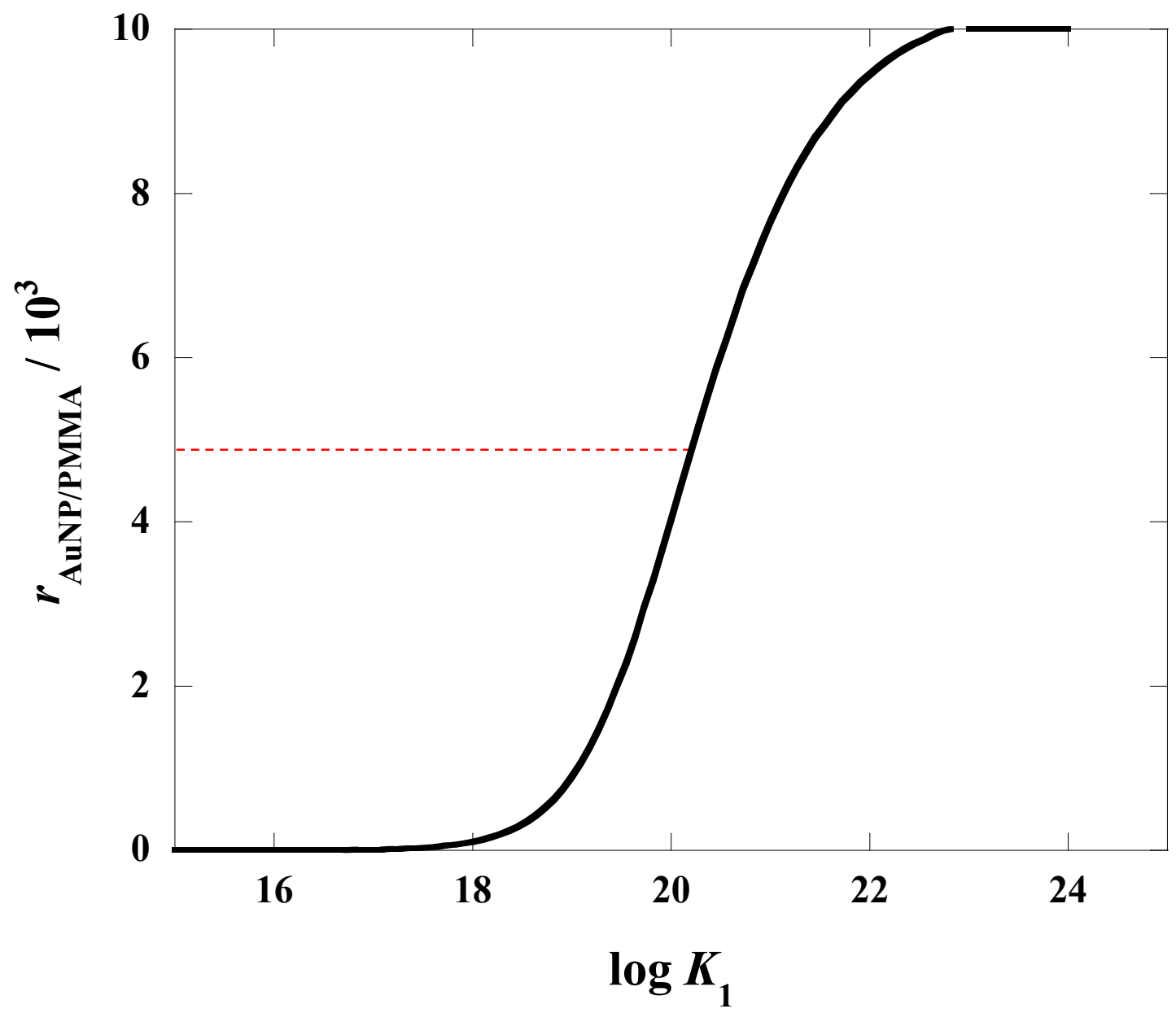

Figure S3 Relationship between $\log K_{1}$ and the number of AuNPs bound on a PMMA at $r_{\mathrm{AuNP} / \mathrm{PMMA}}=10000$. Red broken line represents $n_{\mathrm{AuNP} / \mathrm{PMMA}}=4736 .\left[C_{\mathrm{PMMA}}\right]=3.38 \times$ $10^{-9} \mathrm{M},\left[C_{\text {aptamer }}\right]=3.1 \times 10^{-12} \mathrm{M}$, and $\left[C_{\mathrm{AuNP}}\right]=2.97 \times 10^{-12} \mathrm{M}$ 


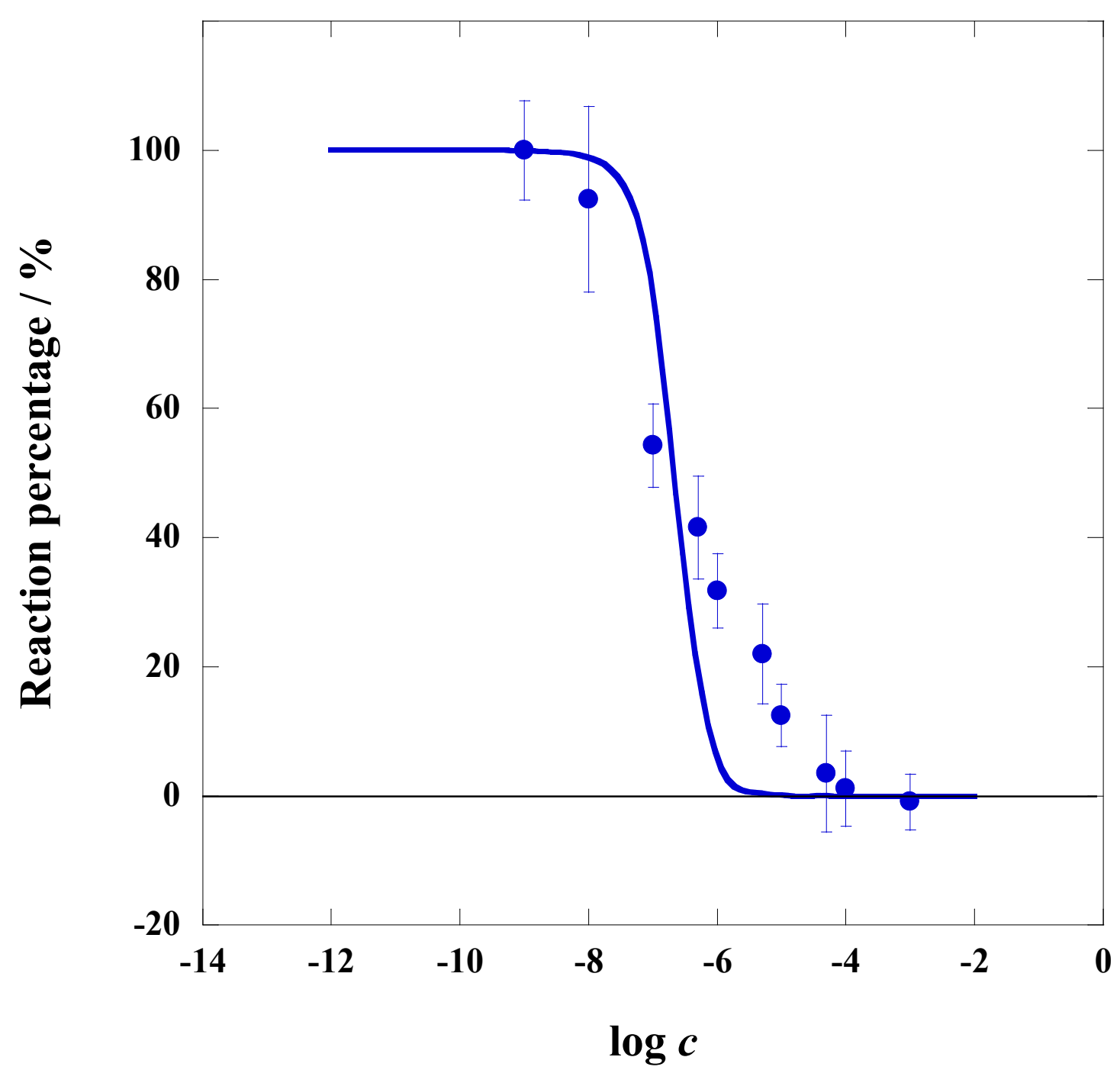

Figure S4 Relationships between the $\log c$ for ATP and the reaction ratio. The curve represents the result of calculation assuming 1:2 aptamer-ATP complexation with $K_{1}=$ $1.58 \times 10^{20} \mathrm{M}^{-2}$ and $K_{2}=1.58 \times 10^{-7} \mathrm{M}$. 


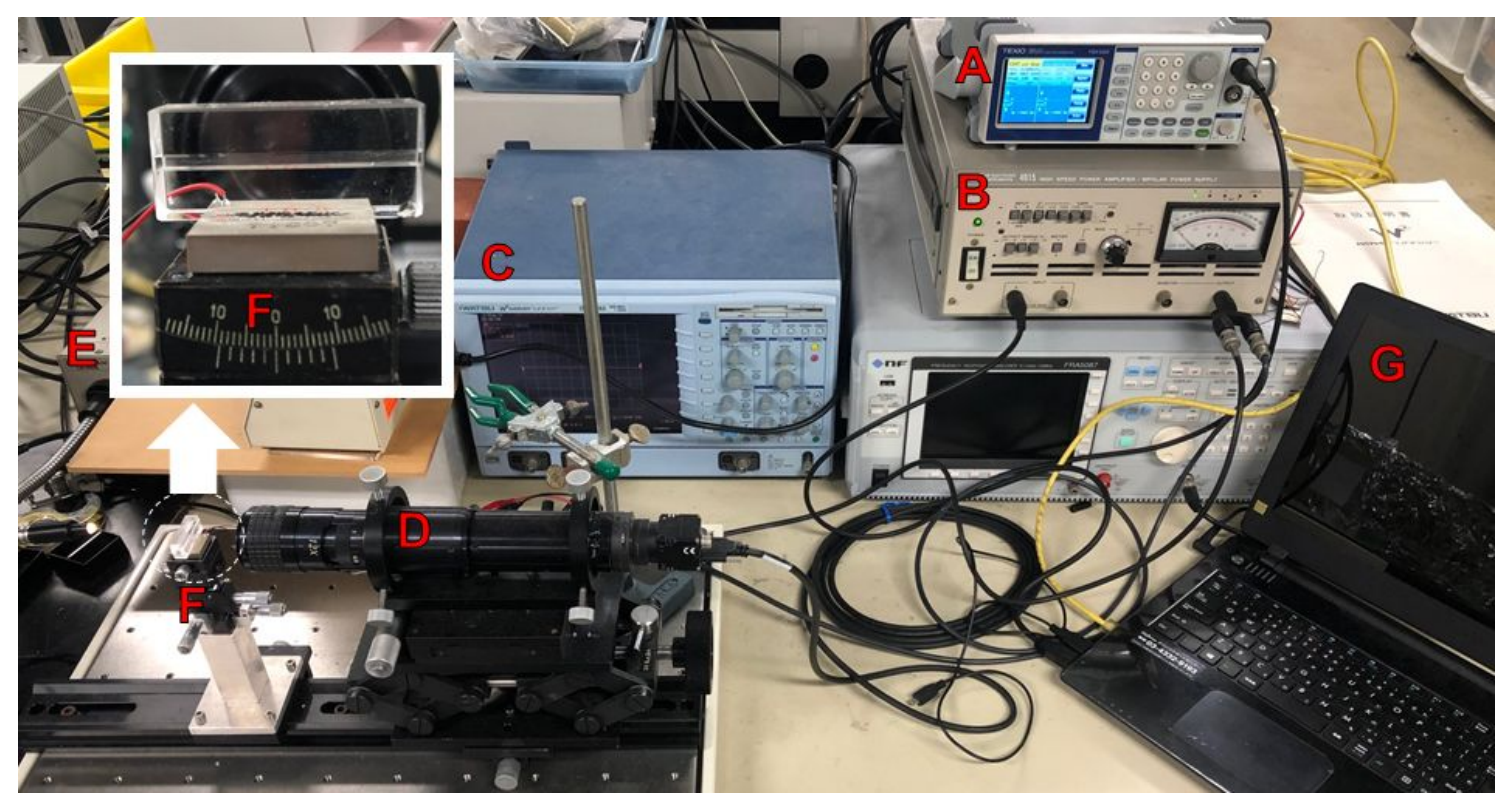

Figure S5 Experimental setup.

(A) Function generator, (B) amplifier, (C) oscilloscope, (D) CCD camera with a zoom lens, (E) light source, $(\mathrm{F})$ cell (magnified image in inset), and (G) computer. The photo was taken by A.Miyagawa. 